\title{
Low Food and Nutrition Literacy (FNLIT): A barrier to dietary diversity and nutrient adequacy in school age children
}

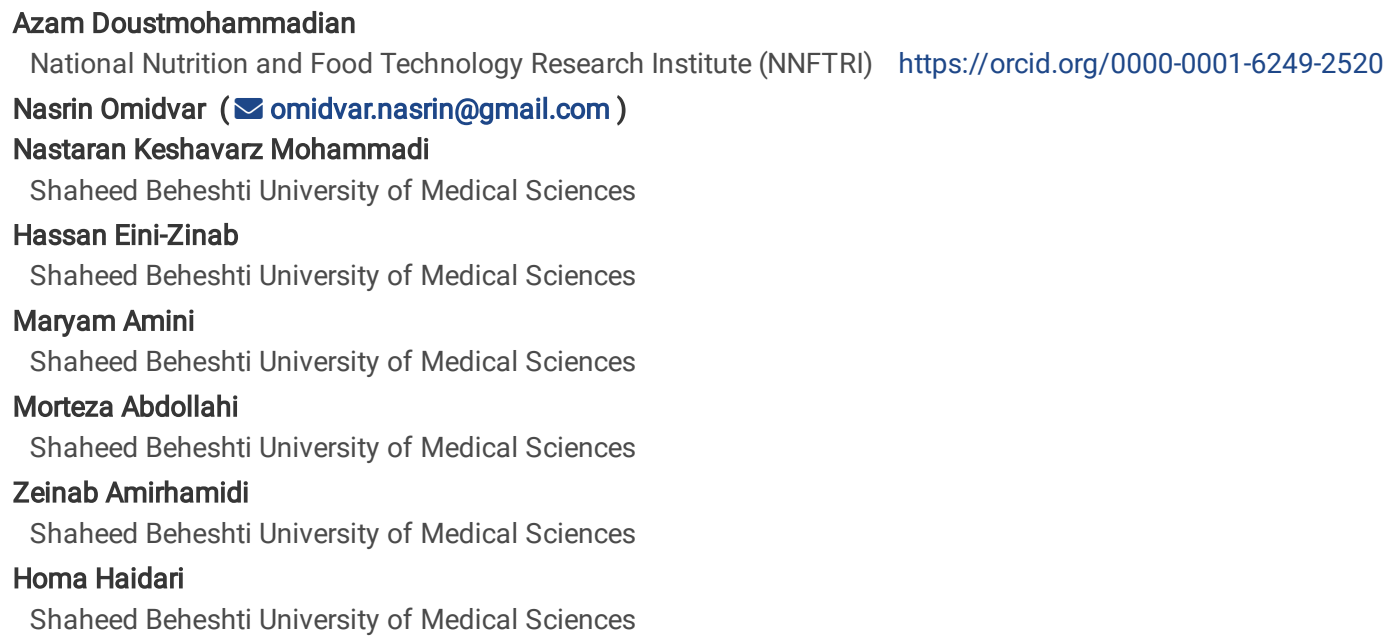

Research article

Keywords: Food and Nutrition Literacy, dietary diversity, nutrient adequacy, school age children, Iran

Posted Date: September 17th, 2019

DOI: https://doi.org/10.21203/rs.2.14552/v1

License: (우 (i) This work is licensed under a Creative Commons Attribution 4.0 International License. Read Full License 


\section{Abstract}

Background: Increasing prevalence of overweight/obesity in children and adolescents over the past two decades has made it a public health concern. Knowledge, skills and critical decision making about food choices and dietary intake, known as food and nutrition literacy (FNLIT) could be one of the keys to improving the outcomes of future interventions in this area. This study aims to assess the relationship between FNLIT and dietary diversity and nutrient adequacy in school-age children in Iran.

Methods: This cross-sectional study was undertaken on 803 Primary school students aged 10-12 years in Tehran, Iran. Socio-economic and household food security characteristics, as well as three 24-hour dietary recalls (two week-days and one weekend) were collected through interviewing students and their mothers/caregivers. FNLIT was measured by a self-administered locally designed and validated questionnaire. Number of servings from food groups and diet diversity score, as well as nutrient adequacy were calculated and compared with recommendations. The association between dietary quality factors and FNLIT were evaluated by logistic regression analysis.

Results: Students with low FNLIT were less likely to meet daily recommended portion of vegetable (OR=2.83, 95\% $\mathrm{Cl}=1.12-7.17)$, meats $(\mathrm{OR}=2.37,95 \%$ $\mathrm{Cl}=1.01-5.55)$ and fruits $(\mathrm{OR}=2.42,95 \% \mathrm{Cl}=1.38-4.25)$ (after adjusting for confounding factors, including demographics, Socioeconomics, physical activity, calorie intake and food security). Moreover, low FNLIT subscales were associated with higher odds of low diversity of fruits (OR=3.82, 95\% $\mathrm{Cl}=1.01-14.42)$, dairies (OR=19.5, 95\% Cl=2.09-182.38), and meats (OR=2.4, 95\% Cl=1.31-4.40). low FNLIT and its subscales were associated with odds of lower level of NAR of protein ( $\mathrm{OR}=2.02,95 \% \mathrm{Cl}=1.02-8.95)$, calcium ( $\mathrm{OR}=2.2,95 \% \mathrm{Cl}=1.16-4.49)$, and vitamin $\mathrm{B} 3(\mathrm{OR}=3.65,95 \% \mathrm{Cl}=1.05-12.69)$, as well as probability of lower level of MAR (OR=2.91, 95\% Cl=1.03-8.23, OR=3.12, 95\% Cl=1.38-7.05), and NAR of vitamin $\mathrm{B} 9(\mathrm{OR}=2.98,95 \% \mathrm{Cl}=1.04-8.51)$, and odds of lower level of $\mathrm{NAR}$ of vitamin $\mathrm{B} 6(\mathrm{OR}=2.30,95 \% \mathrm{Cl}=1.10-4.83)$.

Conclusion: Improving FNLIT in children may help to improve their eating habits and dietary quality for the benefits of good health.

\section{Background}

Prevalence of non-communicable diseases is a public health problem in Iran [1]. Therefore, an important priority for the health sector is capacity building within the public to prevent Non-Communicable Diseases (NCDs) by empowering people to take control of the determinants of their health and disease [2]. Health literacy is considered as one of the most important skills to enable individuals to control health determinants [3]. Due to wide scope of health issues and because of the growing prevalence of chronic diseases related to food and nutrition [4], evidence suggest that one should consider health literacy more specifically [5]. As a result, specific area of health literacy, including food literacy, as well as nutrition literacy has been proposed and conceptualized. "Nutrition literacy" is defined as ability to access, interpret and use nutrition information for making appropriate nutritional health-related decisions [6]. According to Nutbeam's hierarchical model of health literacy [7], nutrition literacy is classified in three levels as functional, interactive and critical nutrition literacy [8]. Functional nutrition literacy is concerned with basic reading and writing skills necessary to understand and follow simple nutrition message. Interactive nutrition literacy is more advanced literacy which includes cognitive and interpersonal skills needed to manage nutrition issues in partnership with professionals. Finally, critical nutrition literacy is ability to analyze nutrition information critically, increase awareness, and participate in action to address barriers [5, 8]. In the other hand, "food literacy" as an emerging term that is defined "collection of inter-related knowledge, skills and behaviors required to plan, manage, select, prepare and eat foods to meet needs and determine food intake" [9]. Vidgen and Gallegos (2014) in their framework noted the indirect link between food literacy and healthy nutrition. For them, food security and the ability to prepare food, improve food choice and pleasure, which in turn, can lead to healthy eating behaviors [9]. Although the two concepts have emerged separately, there are significant overlaps and can complete each other [10]. The elements which are largely drawn from food literacy discourse are extremely relevant to nutrition literacy as a broader concept. The transition from knowledge to practice is viewed as a vital component of either food and nutrition literacy [5]. This is why researchers emphasize on the three dimensions of food and nutrition literacy. In particular, an expanded conceptualization of food and nutrition literacy should be considered in order to integrate emancipatory health strategies into their work, because such efforts will be beneficial for the wider community [5]. Based on the Iranian experts view, the term "food and nutrition literacy" [11] as a combined term have been proposed and adopted to describe a wide range of abilities and skills needed for healthy and responsible nutrition behaviors.

In Iran, nutrition transition has taken place due to urbanization and rapid socio-economic changes and have resulted in a tendency toward a more westernized food pattern, especially in children and adolescents [12]. This general shift in children's diet is characterized as low consumption of fruit and vegetables, fiber-rich foods and dairy products [13], as well as high consumption of fatty, sugary and convenience foods [14]. As a result, dietary intakes of children do not meet national dietary guidelines [15].

Recently, food and nutrition literacy has been considered as an important factor that can have a critical role in shaping children's dietary behaviors [16] and enabling them to have healthy food choices $[9,17]$. Considering today's children food environment, with increased access to fast foods and popularity of processed food products, improving food and nutrition literacy provides an opportunity for them to acquire appropriate skills and act more consciously [18]. Childhood and adolescence is a critical period of life through which dietary patterns are shaped and have the potential to influence long-term health [19]. Identifying the relation between food and nutrition literacy and children dietary intake is important for the development of effective prevention and management strategies in these age groups [20]. Therefore, this study aimed to measure the relation between food and nutrition literacy and dietary intakes in primary school children in the city of Tehran.

\section{Methods}

\section{Study design and setting}


This school-based cross-sectional survey was performed using a multistage random cluster sampling design. The study was conducted in Tehran the capital city of Iran from November to January 2015. The STROBE (Strengthening The Reporting of Observational Studies in Epidemiology) study conduct [21] and participant flow is outlined in Fig 1. The study protocol was approved by the National Nutrition and Food Technology Research Institute's (NNFTRI) ethical committee (No.1394.20/16-10-2015).

\section{Study participants}

The sample included 803 primary school students ( 419 boys and 384 girls) aged 10-12 years (power study $88 \%$ ). The general office of education in Tehran classifies 19-educational-districts into three socioeconomic categories, including: affluent (north of Tehran), mid-level (center of Tehran) and deprived (south of Tehran). The education department in Tehran provided a list of primary schools located within the boundary of the school districts for sampling. A multistage random cluster sampling technique was applied. First, nine districts ( 3 from each of the three socioeconomic areas) were selected by weighting districts according to their student population. Then, 34 public and 10 private schools from these 9 districts were selected with a probability proportional to size of the target population. In the third stage, in each school, 5th and 6th grade students were randomly selected from the enrollment list. Selected students and their parents were invited to take part in the study after signing a written consent letter.

\section{Data collection}

\section{Food and nutrition literacy Assessments}

Food and nutrition literacy (FNLIT) was measured by a valid self-administered questionnaire. The process of development and validation of the FNLIT questionnaire have been reported elsewhere [11]. The questionnaire consisted of 4 true-false and 42 likert-type items within two cognitive and skill domains. Cognitive domain included two sub-scales: understanding food and nutrition information (10 items) and nutritional health knowledge (5 items). Skill domain consisted of four sub-scales: functional food and nutrition literacy (10 items), interactive food and nutrition literacy (7 items), food choice (6 items) and critical food and nutrition literacy (4 items). Finally, Food label literacy was evaluated by 4 true-false items. In order to determine the optimal food and nutrition literacy cut-off scores for distinguishing between high and low levels of FNLIT, a Receiver Operating Characteristic (ROC) analysis was used. This analysis compared the performance of the scale against Healthy Eating Index (HEI) scores as a criterion [22, 23] to define the cutoff points of FNLIT scale. $\mathrm{HEl}$ is a measure of diet quality that assesses one's concordance with the dietary guidelines [24]. It has been used in research to better understand relationships between nutrients, foods and/or dietary patterns and health-related outcomes [25-27]. Therefore, HEl identified as the appropriate indicator to detect the cutoff point of FNLIT scale. The ROC curve demonstrated the relationship between sensitivity (the proportion of true low food and nutrition literacy) and specificity (proportion of true high food and nutrition literacy) across the full range of food and nutrition literacy values. The sum score with the highest combination of sensitivity and specificity [28] was identified as the optimal cut-off score. ROC analysis was conducted for the high and low cut offs of the total score of FNLIT, separately. The resulting three levels of FNLIT were low $(\leq 51)$, medium $(>51-<74)$ and high $(\geq 74)$, where the FNLIT score ranged from 25.8 to 96.8 [29].

\section{Dietary intake assessments}

Dietary data were collected by three 24-hour dietary recalls (two week-days and one holiday) by trained nutritionists. Multiple probe methods were used to complete 24-hour dietary recalls, including diverse portion size descriptions, a food album, home measures and detailed food preparation methods by interviewing the students and their mothers/caregivers. To identify misreporting, the age and sex-specific cut-off points proposed by Strain et al. [30] for the ratio of reported energy intake and predicted basal metabolic rate (estimated by Schofield equations [31]) were used. After excluding over and under reporters, the assessment was conducted for 493 students.

Dietary intake adequacy-Food intakes were translated into energy and macronutrients. The nutrient adequacy ratio (NAR,\%) was calculated for each of the 11 micronutrients (vitamins A, B6, B12 and C, niacin, thiamin, riboflavin, folate, calcium, iron and zinc), energy and protein. NAR was calculated as the intake of a nutrient divided by the recommended intake for that nutrient (RNI), using WHO/FAO recommended intakes [32] which are set at two standard deviations above the average requirements. In the case of iron and zinc, the category for moderate bioavailability was used. Mean adequacy ratio (MAR, \%) was calculated as a measure of the adequacy of overall diet, where MAR is the sum of each NAR (truncated at 100\%) divided by the number of nutrients (excluding energy and protein) [22]. For both NAR and MAR a value of $100 \%$ is ideal since it means that the intake is same as the requirement.

Assessing compliance with dietary recommendation- The total number of individual foods consumed were grouped into five food groups based on the USDA food grouping scheme [33] (Table 1): 1) dairy products, 2)protein foods (i.e., meat, poultry, seafood, eggs, nuts and seeds and legumes), 3) fruits (whole fruits, dried fruits? and fruit juices), 4) vegetables (starchy vegetables were included), and 5) grains (i.e., cereals, cereal products and other starchy foods). Mixed dishes were analyzed for their ingredients, which were further allocated to the relevant food group. Following the calculation of the number of portions consumed from each one of the five core food groups, study participants were categorized based on whether they were meeting or not USDA MyPlate dietary intake recommendations [33].

Dietary Diversity Score (DDS)-DDS was calculated as part of the pyramid serving database that was categorized into 23 broad food groups. Each of the 5 broad food categories received a maximum diversity score of 2 of the 10 possible score points. To be counted as a "consumer" for any of the food groups 
categories, a respondent needed to consume at least one-third serving, as defined by Food Guide Pyramid quantity criteria, at any time during a 3-day survey period [34].

\section{Covariates}

A number of evidence-based covariates were considered in the study [6, 35-37]. Anthropometric measurements were taken according to World Health Organization (WHO) recommendations [38]. BMI-Z-score for age and sex was calculated by WHO AnthroPlus, 2007 [39]. Children's weight status were reported in 4 category as: thin ( $z$ score: $<2 S D$ ), normal ( $z$ score: $\geq-2 S D$ and $\leq 1 S D$ ), overweight ( $z$ score: $>1 S D$ and $\leq 2 S D$ ) and obese ( $z$ Score: $>2 S D$ ). Physical activity was measured through interviewing children by the locally validated version of Child and Adolescent International physical activity questionnaires [40, 41]. Physical activity was expressed as metabolic equivalents hour/day (METs-h/day) and categorized as tertile (Mean T1: 33, Mean T2: 38.37, Mean T3: 47.71). Household food security status was measured using a locally validated 18-item USDA's Household Food Security Survey Module through interviewing mothers $[42,43]$. This measure identifies the ability of households to obtain and conserve food over the past 12 months. The USDA module was completed through face-to-face or telephone-interview with mothers. Based on the scale, households were categorized into: food secure (FS) (raw score 0-2); food insecure(FI) [43] without hunger (raw score of 3-7); and FI [43] with moderate hunger (raw score of 8-12); FI with severe hunger (raw score of 13-18). Due to low prevalence of FI with moderate and severe hunger, they were grouped as one.

Other covariates of interest included age, birth order ( $<2$ and $\geq 2)$, family size $(<4,4$ and $>4)$, puberty stage for girls (pre menarche and post menarche), father's age tertile (T1: $30-40, T 2: 41-45$ and T3: $\geq 46$ years old), mother's age tertile (T1: $23-35, T 2: 36-40$ and T3: $\geq 41$ years old), ethnicity (Fars, Azeri, luri, Kurdish, Fars-Azeri and other ethnicities), parents' education (illiterate or $\leq 5$ years, $6-9$ years or diploma, Associate's degree or higher), father's job position (worker, employee, self-manager, high rank employee and retired), mother's employment status (housewife and work outside the home), other sources of income of family members (yes, no), house ownership status (owner, tenant, mortgage and other), and having financial support (yes, no).

\section{Statistical Analysis}

Dietary intakes analysis was performed in plausible reported energy intakes. A food-grouping scheme was designed for all food items using Nutritionist IV and Iranian food composition table [44]. Normality of distribution was evaluated using the Kolmogorov-Smirnov test. Data were presented as means and standard deviations for continuous variables and frequencies and percentages for categorical variables. Chi square test was used for analysis of general characteristics of participants, comparison percentages with consumption below the recommended portions for each food group between two sexes. Independent sample t-test was used to evaluate the differences between continuous variable between two sexes. Binary logistic regression adjusting for study covariates was also used to estimate the association between food and nutrition literacy and food groups' intake. Multinomial logistic regression analysis adjusting for confounding factors of the lower two tertiles compared with the higher tertile of MAR, NAR and Diet Diversity Score (DDS) was conducted. Two-tailed tests were conducted and P values lower than 0.05 were considered as statistically significant. All statistical analysis was performed using SPSS 21.0 (SPSS Inc., Chicago, Illinois, US).

\section{Results \\ Characteristics of the Study Participants}

Background characteristics of the studied children are summarized in Tables S1. A total of 803 students (419 boys) participated in the study. Mean age of students was $11.28 \pm 0.65$ years. Girls and boys did not differ significantly in demographic characteristics and socio-economic status, except for father education $(p<0.001)$, father job position $(p<0.001)$ and house ownership status $(P=0.005)$. Boys were significantly more physically active as compared to girls $(P<0.001)$. There were a higher number of girls in the first tertile of physical activity while greater number of boys was in the highest tertile. Based on BMI-Z-score for age and sex, $26.7 \%$ of the children were overweight and $23.9 \%$ were obese which differed with sex $(P<0.001)$. Only $1.9 \%$ of the children were thin while $47.6 \%$ were normal weight.

\section{Food and Nutrition Literacy (FNLIT)}

FNLIT characteristics of the participants are presented in Table 2. Approximately $11.6 \%$ of students were categorized as having low food and nutrition literacy. Almost $25 \%$ of students had low scores in FNLIT skill domain, while the majority scored moderate to high in cognitive domain ( $97.4 \%$ ). Among subscales of FNLIT skill domain, high proportion of students had low scores in critical FNLIT (42.2\%) as well as food label literacy (81.1\%). However, they scored better in food choice literacy and only $7.8 \%$ scored low. A significantly higher proportion of girls (71\%) had high level of food choice literacy as compared to boys $(67.1 \%)(p=0.002)$. On the contrary, boys scored higher in critical food and nutrition literacy compared to girls $(22.9 \%$ vs $16.8 \%$, $p=0.01)$.

\section{Compliance with dietary recommendations}

Inadequate intakes were observed for several food groups (Table 3). The majority of children did not meet the minimum recommended daily portions for dairy $(91.7 \%)$ and protein foods (81.7\%). Boys were reported to have a higher average consumption of portions from protein foods and grains groups compared to girls $(p=0.001)$, while higher average consumption of portions from vegetables group was observed in girls compared to boys $(p=0.04)$. The percentage of children who did not meet the recommended servings from protein foods was higher in girls $(p=0.01)$. On the contrary, the percentage of boys

Page $4 / 14$ 
not meeting the recommended servings from vegetables was significantly higher in boys compared to girls ( $26 \%$ compared to $18 \%, p=0.03)$. Adjusted binary regression logistic (Table 4) showed that students with low score of understanding of food and nutrition information (as a component of cognitive domain) were more likely to meet inadequate portion of vegetable $(\mathrm{OR}=2.83,95 \% \mathrm{Cl}=1.12-7.17)$ and meat $(\mathrm{OR}=2.37,95 \% \mathrm{Cl}=1.01-5.55) \mathrm{groups}$. Students with low functional nutrition literacy scores were more likely to have inadequate intake of fruit group $(\mathrm{OR}=2.42,95 \% \mathrm{Cl}=1.38-4.25)$.

\section{Dietary intake adequacy}

MAR and NAR of certain nutrients by sex are presented in Fig 2. The MAR, and the NAR of energy, vit B12, B2, Zn was significantly lower in boys compared with girls $(\mathrm{p}<0.05)$. This pattern was reverse for the NAR of protein $(\mathrm{P}<0.001)$. The multinomial-adjusted odds ratio $(95 \% \mathrm{Cl})$ of the lower two tertiles compared with the highest tertile of MAR and NAR of certain nutrients are presented in Table 5. Low levels of FNLIT was significantly associated with odds of lower level of NAR of protein ( $\mathrm{OR}=2.02,95 \% \mathrm{Cl}=1.02-8.95)$. Low level of Understanding Food and Nutrition Information (UFNI) significantly increased the probability of having lower level of MAR and NAR of vitamin B9 $(\mathrm{OR}=2.91,95 \% \mathrm{Cl}=1.03-8.23, \mathrm{OR}=2.98,95 \% \mathrm{Cl}=1.04-8.51$ respectively). $\mathrm{Low}$ level of Functional Food and Nutrition Literacy (FFNL) was significantly associated with odds of lower levels of MAR and NAR of vitamin B6 (OR $=3.12,95 \% \mathrm{Cl}=$ $1.38-7.05, \mathrm{OR}=2.30,95 \% \mathrm{Cl}=1.10-4.83$, respectively). Low level of FFNL was also significantly associated with odds of lower two tertiles compared with higher tertile of NAR of calcium ( $\mathrm{OR}=2.98,95 \% \mathrm{Cl}=1.46-6.11, \mathrm{OR}=2.34,95 \% \mathrm{Cl}=1.16-4.76$ respectively). Low level of Food Choice Literacy ( $\mathrm{FCL}$ ) was significantly associated with probability of lower level of NAR of vitamin B3 (OR $=3.65,95 \% \mathrm{Cl}=1.05-12.69)$. Low level of Food Label Literacy (FLL) was significantly associated with probability of lower level of NAR of calcium $(\mathrm{OR}=2.28,95 \% \mathrm{Cl}=1.16-4.49)$.

\section{Dietary diversity}

Multinomial logistic regression analysis adjusted for confounding factors of the lower two tertiles compared with the higher tertile of Diet Diversity Score (DDS) are presented in Table 6. Low level of Nutritional Health Knowledge (NHK) was significantly associated with probability of lower fruit diversity score $(\mathrm{OR}=3.82,95 \% \mathrm{Cl}=1.01-14.42)$. Low level of Functional Food and Nutrition Literacy (FFNL) was significantly associated with odds of lower level of DDS, fruit diversity score $(\mathrm{OR}=2.72,95 \% \mathrm{Cl}=1.38-5.34, \mathrm{OR}=4.87,95 \% \mathrm{Cl}=2.13-11.08$, respectively) and dairy diversity score (the first tertile of dairy diversity; $\mathrm{OR}=19.55,95 \% \mathrm{Cl}=2.09-182.38$, the second tertile of dairy diversity; $\mathrm{OR}=11.49,95 \% \mathrm{Cl}=1.21-108.60)$. Low level of Interactive Food and Nutrition Literacy (IFNL) was significantly associated with probability of lower meat diversity score $(\mathrm{OR}=2.48,95 \% \mathrm{Cl}=1.34-4.57)$. Low level of Food Label Literacy (FLL) was also significantly associated with probability of lower meat diversity score $(\mathrm{OR}=2.40,95 \% \mathrm{Cl}=1.31-4.40)$.

\section{Discussion}

The present study showed that low food and nutrition literacy can be a barrier to compliance with dietary recommendations in school age children. Students with low understanding of food and nutrition information and low functional food and nutrition literacy were more likely to have inadequate intake of vegetable, meat and fruit group. Previous research has shown that high food literacy is associated with increased consumption of fruits and vegetables [45, 46]. Children and adolescents who assisted to prepare meals were more likely to engage in food preparation-related behaviors such as buying fresh vegetables, writing grocery lists and preparing meals with chicken, fish or vegetables [47]. Besides, food and nutrition literacy skills encompass the ability to obtain factual dietary information and develop an understanding of factors that can enhance or inhibit nutritional health [5] and may promote diet diversity and nutrient adequacy through improving understanding of available food and nutrition information and adherence to the dietary guidelines [5]. Low level of food label literacy was significantly associated with probability of lower level of meat group diversity and NAR of calcium, the two major limiting nutrients in the Iranian's diet [48]. A systematic review found a consistent link between the use of nutrition labels and healthier diets [49]. There is evidence that food labeling helps consumers make better judgment about foods and make healthier choice of food groups [50, 51].

Food label literacy was one of the weakest areas among the studied children. However, the question is to what degree food labeling is an appropriate approach and what type of information and labeling approaches would be helpful for children. Previous reports have identified food label reading as one of the key areas to improve food choices and dietary intakes in children [50]. In Iran, mandatory nutrition labeling for food products has recently been initiated while there are still gaps in its regulatory policy [52]. Besides, this concept and its application has not been entered public education to empower individuals in making healthy food choices [53]. This may explain low scores observed in the study population with regard to questions on food labels. The considerable proportions of students with low food and nutrition literacy in skill domain imply a gap in food and nutrition skill development in primary school curriculums in the country. This is not a surprise as based on content analysis of primary school textbooks in Iran nutritional content of school textbooks was mainly theoretical and impractical [53]. This leads to many students with high food and nutrition knowledge, but with performance gaps in their health dietary patterns. Even though, nutrition knowledge is a key component of health literacy [54] and has been identified as essential for behavior change [55], knowledge alone is generally not sufficient to produce sustained behavior change in complex behaviors [55]. So, food and nutrition literacy subscale-based interventions should be designed to improve students' skills and nutrition behaviors. For example, the results provide a reminder of the need to support improvements in food choices and dietary behaviors by helping young people to develop skills such as those required to interpret food labeling. Findings of the current study showed some clear sex-specific differences in intakes of grains, protein foods and vegetables, with intake for grains and protein foods was higher in boys and intakes of vegetables was higher in girls. These results are consistence with Manios et al (2015) study which found boys had higher average consumption of portions from almost all food groups compared to girls (with the only exception being the consumption of fruits) [56]. The results of the study showed that consumption of dairy products was below the recommendations for the majority of children (91\%) [57]. Regarding consumption of food groups, the lowest compliance with the recommendations among girls was in protein foods, while in boys the lowest compliance with the recommendations was in vegetables. Similarly, in the Emirati 6 to 18-year-old children and adolescents survey, the proportion of participants who did not meet vegetable intake recommendations was substantial ( $80.1 \%$ among 9 to13-year-old girls and 100\% among 9 to18-year-old boys). Furthermore, mean

Page 5/14 
consumption of lean meats and beans was less than the MyPyramid recommendations for all the subgroups, except in females 6 to 8 years old. [58]. The MAR, and the NAR of energy, vit B12, B2, Zn was significantly lower in boys compared with girls except for NAR of protein. Patterns observed across MAR and NAR of nutrients could be probably attributed to sources of the evaluated nutrient; for example percentages with inadequate dietary intakes in food protein and vegetables group were found to be higher for boys compared with girls. Campmans-Kuijpers et al [59] observed that children who had a high intake of one nutrient tended to have adequate intakes of the other nutrients as well. The current study may be the first study exploring the association between food and nutrition literacy and dietary intakes in children. However, because of its cross-sectional design, it is not possible to establish any causal contributions of food and nutrition literacy on children's dietary intakes.

\section{Conclusion}

This study demonstrates that the low level of food and nutrition literacy is associated with nutritional inadequacy and low diet diversity scores and may play an important role in shaping children's dietary intake. Since food and nutrition literacy is expected to have effect on one's ability to assess information when choosing foods, comprehend food labels, and apply dietary recommendations. Therefore, it is important for educators and program planners to assess and enhance food and nutrition literacy of young people. Stakeholders, including the policy makers, food manufacturers, health providers, educators, and businesses should also play their roles so as to achieve a bigger impact on future generation.

\section{Abbreviations}

FNLIT, food and nutrition literacy; NCDs, non-communicable diseases; ROC, receiver operating characteristic; HEI, healthy eating index; NAR, nutrient adequacy ratio; RNI, recommended intake for that nutrient; MAR, mean adequacy ratio; DDS, dietary diversity score; BMI, body mass index; METs-h/day, metabolic equivalents hour/day; UFNI, Understanding Food and Nutrition Information; NHK, nutritional health knowledge; FFNL functional food and nutrition literacy; IFNL, interactive food and nutrition literacy; FCL, food choice literacy; CFNL, critical food and nutrition literacy; FLL, food label literacy.

\section{Declarations}

\section{Ethics approval and consent to participate}

The study was approved by National Nutrition and Food Technology Research Institute's (NNFTRI's) ethics committee (approval code was IR.SBMU.nnftri.Rec.1394.20). Written informed consent was obtained from students and their parents, prior to commencement of the survey.

\section{Consent for publication}

Not applicable.

\section{Availability of data and material}

We do not wish to make the data available as we are still using the data for other analyses. However, the datasets used during the current study are available from the corresponding author on reasonable request.

\section{Competing interests}

The authors declare that they have no competing interests.

\section{Funding}

This work was supported by the approval and funding of the Shahid Beheshti University of Medical Sciences, National Nutrition and Food Technology Research Institute (NNFTRI) (grant nomber.1394.20/16-10-2015).

\section{Authors' contributions}

$A D$ was responsible for analysing and interpreting the data, drafting and editing the article. NO, NKM, HE-Z carried out the study design and analysis. $A D, Z A$, $\mathrm{HH}$, collected data. AD, NO, NKM, MA1, MA2 and HE-Z participated in conceiving and designing the research, revising the article and collecting data. All authors read and approved the final manuscript.

\section{Acknowledgements}

The authors hereby express their appreciation to Shahid Beheshti University of Medical Sciences, National Nutrition and Food Technology Research Institute (NNFTRI) for funding the study. All coordinators, interviewers, and students who participated in this study are appreciated.

\section{References}


1.Sarrafzadegan N, Baghaei A, Sadri G, Kelishadi R, Malekafzali H, Boshtam M, Amani A, Rabie K, Moatarian A,Rezaeiashtiani A. Isfahan healthy heart program: Evaluation of comprehensive, community-based interventions for non-communicable disease prevention. Prevention and Control, 2006. 2(2), 7384

2.Ali MK, Rabadan-Diehl C, Flanigan J, Blanchard C, Narayan KM,Engelgau M. Systems and capacity to address noncommunicable diseases in low- and middle-income countries. Sci Transl Med, 2013. 5(181), 181cm4.PMID: 23596201 doi: 10.1126/scitransImed.3005121

3.WHO. Jakarta Declaration on Health Promotion into the 21st Century. Switzerland, Geneva: World Health Organisation.. 1997,

4.Popkin BM. What can public health nutritionists do to curb the epidemic of nutrition-related noncommunicable disease? Nutr Rev, 2009. 67 Suppl 1, S7982.doi: $0.1111 / \mathrm{j} .1753-4887.2009 .00165 . x$

5.Velardo S. The Nuances of Health Literacy, Nutrition Literacy, and Food Literacy. J Nutr Educ Behav, 2015. 47(4), 385-9 e1.doi:10.1016/j.jneb.2015.04.328

6.Zoellner J, Connell C, Bounds W, Crook L,Yadrick K. Nutrition literacy status and preferred nutrition communication channels among adults in the Lower Mississippi Delta. Prev Chronic Dis, 2009. 6(4), A128.PMID:19755004

7.Nutbeam D. The evolving concept of health literacy. Social science \& medicine, 2008. 67(12), 2072-2078.doi:10.1016/j.socscimed.2008.09.050

8.Pettersen S, Kjøllesdal, J. G., \& Aarnes, S. B. Measuring nutrition literacy. Paper presented at the 19th International Conference of Nutrition, Bangkok, Thailand. 2009,

9.Vidgen HA,Gallegos D. Defining food literacy and its components. Appetite, 2014. 76, 50-9.doi:10.1016/j.appet.2014.01.010

10.Krause C, Sommerhalder K, Beer-Borst S,Abel T. Just a subtle difference? Findings from a systematic review on definitions of nutrition literacy and food literacy. Health Promot Int, 2018. 33(3), 378-389.doi:10.1093/heapro/daw084

11.Doustmohammadian A, Omidvar N, Keshavarz-Mohammadi N, Abdollahi M, Amini M,Eini-Zinab H. Developing and validating a scale to measure Food and Nutrition Literacy (FNLIT) in elementary school children in Iran. PLoS One, 2017. 12(6), e0179196.doi.org/10.1371/journal.pone.0179196

12.Ghassemi H, Harrison G,Mohammad K. An accelerated nutrition transition in Iran. Public Health Nutr, 2002. 5(1A), 149-55.doi:10.1079/phn2001287

13.Diethelm K, Jankovic N, Moreno LA, Huybrechts I, De Henauw S, De Vriendt T, Gonzalez-Gross M, Leclercq C, Gottrand F, Gilbert CC, Dallongeville J, Cuenca-Garcia M, Manios Y, Kafatos A, Plada M,Kersting M. Food intake of European adolescents in the light of different food-based dietary guidelines: results of the HELENA (Healthy Lifestyle in Europe by Nutrition in Adolescence) Study. Public Health Nutr, 2012. 15(3), 38698.doi:10.1017/s1368980011001935

14.Savige GS, Ball K, Worsley A,Crawford D. Food intake patterns among Australian adolescents. Asia Pac J Clin Nutr, 2007. 16(4), 738-47.PMID: 18042537 15.Brady LM, Lindquist CH, Herd SL,Goran MI. Comparison of children's dietary intake patterns with US dietary guidelines. Br J Nutr, 2000. 84(3), 3617.PMID: 10967615

16. Hawkes C,Popkin BM. Can the sustainable development goals reduce the burden of nutrition-related non-communicable diseases without truly addressing major food system reforms? BMC Med, 2015. 13, 143.10.1186/s12916-015-0383-7

17.Nutbeam D,Kickbusch I. Advancing health literacy: a global challenge for the 21st century. Health promotion international, 2000. 15(3), 183184.doi:10.1016/j.socscimed.2008.09.050

18.Vidgen HA,Gallegos D. What is food literacy and does it influence what we eat: a study of Australian food experts. Queensland University of Technology, Brisbane, Queensland, Australia. Available online: http://eprints.qut.edu.au/45902/. 2011,

19.Lake AA, Mathers JC, Rugg-Gunn AJ,Adamson AJ. Longitudinal change in food habits between adolescence (11-12 years) and adulthood (32-33 years): the ASH30 Study. J Public Health (Oxf), 2006. 28(1), 10-6.PMID: 16473923 doi: 10.1093/pubmed/fdi082

20.Vaitkeviciute R, Ball LE,Harris N. The relationship between food literacy and dietary intake in adolescents: a systematic review. Public Health Nutr, 2015. 18(4), 649-58.doi:10.1017/s1368980014000962

21.Von Elm E, Altman DG, Egger M, Pocock SJ, Gøtzsche PC, Vandenbroucke JP,Initiative S. The Strengthening the Reporting of Observational Studies in Epidemiology (STROBE) Statement: guidelines for reporting observational studies. International Journal of Surgery, 2014. 12(12), 1495-1499

22. Hatloy A, Torheim L,Oshaug A. Food variety $Đ$ a good indicator of nutritional adequacy of the diet? A case study from an urban area in Mali, West Africa. Eur J Clin Nutr, 1998. 52, 891-8.PMID: 9881884

23.Santiago-Torres M, Adams AK, Carrel AL, LaRowe TL,Schoeller DA. Home food availability, parental dietary intake, and familial eating habits influence the diet quality of urban Hispanic children. Child Obes, 2014. 10(5), 408-15.PMID: 25259675 PMCID: PMC4195232 doi:10.1089/chi.2014.0051 
24.USDA. Dietary Guidelines Advisory Committee. Report of the Dietary Guidelines Advisory Committee on the dietary guidelines for Americans, 2010, to the Secretary of Agriculture and the Secretary of Health and Human Services. Washington, DC: US Department of Agriculture, Agricultural Research Service. 2010,

25.Huffman FG, De La Cera M, Vaccaro JA, Zarini GG, Exebio J, Gundupalli D,Shaban L. Healthy Eating Index and Alternate Healthy Eating Index among Haitian Americans and African Americans with and without Type 2 Diabetes. J Nutr Metab, 2011. 2011, 398324.PMID: 22187639 PMCID: PMC3236495 doi: $10.1155 / 2011 / 398324$

26.Shah BS, Freeland-Graves JH, Cahill JM, Lu H,Graves GR. Diet quality as measured by the healthy eating index and the association with lipid profile in lowincome women in early postpartum. J Am Diet Assoc, 2010. 110(2), 274-9.PMID: 20102856 doi: 10.1016/j.jada.2009.10.038

27.Chiuve SE, Fung TT, Rimm EB, Hu FB, McCullough ML, Wang M, Stampfer MJ,Willett WC. Alternative dietary indices both strongly predict risk of chronic disease. J Nutr, 2012. 142(6), 1009-18.PMID: 22513989 PMCID: PMC3738221 doi: 10.3945/jn.111.157222

28.Youden WJ. Index for rating diagnostic tests. Cancer 3, 32-35. 1950,

29.Doustmohammadian A, Keshavarz Mohammadi N, Omidvar N, Amini M, Abdollahi M, Eini-Zinab H, Amirhamidi Z, Esfandiari S,Nutbeam D. Food and nutrition literacy (FNLIT) and its predictors in primary schoolchildren in Iran. Health Promot Int, 2018.doi:10.1093/heapro/day050

30.Strain JJ, Robson PJ, Livingstone MB, Primrose ED, Savage JM, Cran GW,Boreham CA. Estimates of food and macronutrient intake in a random sample of Northern Ireland adolescents. Br J Nutr, 1994. 72(3), 343-52.PMID: 7947651

31.Schofield, W. N. Predicting basal metabolic rate, new standards and review of previous work. Hum. Nutr. Clin. Nutr. 1985, 39 (suppl 1), 5-41.,

32.Food and Agriculture Organization (FAO)/World Health Organization (WHO). Human Vitamin and Mineral Requirements. Report of a Joint FAO/WHO Expert Consultation. Rome: FAO, 2002.,

33.USDA. US Department of Health and Human Services; US Department of Agriculture. 2015-2020 Dietary Guidelines for Americans. 8th ed. Washington, DC: US Dept of Health and Human Services; December 2015. http://www.health.gov/DietaryGuidelines.. 2015,

34. Haines PS, Siega-Riz AM,Popkin BM. The Diet Quality Index revised: a measurement instrument for populations. Journal of the American Dietetic Association, 1999. 99(6), 697-704

35.Geboers B, de Winter AF, Luten KA, Jansen CJ,Reijneveld SA. The association of health literacy with physical activity and nutritional behavior in older adults, and its social cognitive mediators. Journal of health communication, 2014. 19(sup2), 61-76

36.Bostock S,Steptoe A. Association between low functional health literacy and mortality in older adults: longitudinal cohort study. BMJ, 2012. 344, e1602.PMID: 22422872 PMCID: PMC3307807

37.Kim SY, Sim S, Park B, Kong IG, Kim JH,Choi HG. Dietary Habits Are Associated With School Performance in Adolescents. Medicine (Baltimore), 2016. 95(12), e3096.PMID: 27015180 PMCID: PMC4998375 doi:10.1097/md.0000000000003096

38.World Health Organization. Multicentre Growth Reference Study Group. WHO Child Growth Standards: Length/Height-for-Age, Weight-for-Age, Weight-forLength, Weight-for-Height and Body Mass Index-for-Age: Methods and Development. Geneva, Switzerland: WHO; 2006.

39.World Health Organization. AnthroPlus software, software for assessing growth and development of the world's children,Geneva: WHO.

40.Aadahl M,Jørgensen T. Validation of a new self-report instrument for measuring physical activity. Medicine and science in sports and exercise, 2003. 35(7), 1196-1202

41.Kelishadi R, Rabiei K, Khosravi A, Famouri F, Sadeghi M, Rouhafza H,Shirani S. Assessment of physical activity of adolescents in Isfahan. 2001,

42.Bickel G, Nord M, Price C, Hamilton W,Cook J. Guide to measuring household food security. Guide to Measuring Household Food Security in the United States: Revised 2000. No. 6. March 2000. USDA, Food and Nutrition Services, Alexandria, VA., 2000,

43.Rafiei M, Nord M, Sadeghizadeh A,Entezari MH. Assessing the internal validity of a household survey-based food security measure adapted for use in Iran. Nutrition journal, 2009. 8(1), 1

44.Azar M,Sarkisian E. Food Composition Table of Iran. Tehran: National Nutrition and Food Research Institute, Shaheed Beheshti University. 1980. 65,

45.Burrows TL, Lucas H, Morgan PJ, Bray J,Collins CE. Impact Evaluation of an After-school Cooking Skills Program in a Disadvantaged Community: Back to Basics. Can J Diet Pract Res, 2015. 76(3), 126-32.10.3148/cjdpr-2015-005

46.Utter J, Denny S, Lucassen M,Dyson B. Adolescent Cooking Abilities and Behaviors: Associations With Nutrition and Emotional Well-Being. J Nutr Educ Behav, 2016. 48(1), 35-41 e1.PMID: 26411900 doi:10.1016/j.jneb.2015.08.016 
47.Laska MN, Larson NI, Neumark-Sztainer D,Story M. Does involvement in food preparation track from adolescence to young adulthood and is it associated with better dietary quality? Findings from a 10-year longitudinal study. Public Health Nutr, 2012. 15(7), 1150-8.PMID: 22124458 doi:10.1017/s1368980011003004

48.Azizi H, Asadollahi K, Esmaeili ED,Mirzapoor M. Iranian dietary patterns and risk of colorectal cancer. Health promotion perspectives, 2015. 5(1), 72

49.Campos S, Doxey J,Hammond D. Nutrition labels on pre-packaged foods: a systematic review. Public Health Nutr, 2011. 14(8), 1496-506.PMID: 21241532 doi: $10.1017 /$ s1368980010003290

50.Talagala IA,Arambepola C. Use of food labels by adolescents to make healthier choices on snacks: a cross-sectional study from Sri Lanka. BMC Public Health, 2016. 16, 739.PMID: 27502411 PMCID: PMC4977762 doi:10.1186/s12889-016-3422-1

51.Steyn NP, Nel J, Labadarios D, Maunder EM,Kruger HS. Which dietary diversity indicator is best to assess micronutrient adequacy in children 1 to 9 y? Nutrition, 2014. 30(1), 55-60.PMID: 24290599 doi:10.1016/j.nut.2013.06.002

52.Delshadian Z, Koushki M, Mohammadi R,Mrtazavian A. Evaluation of food labeling for dairy, meat and fruit juice products launched in Tehran market. Iranian journal of food science and technology, 2015. 13(1), 83-90

53.Omidvar N, Amini M, Zahedi-Rad M,Khatam A. Content analysis of school textbooks in a view of improving nutritional knowledge and skills of primary school children. The 2th international and the 14th Iranian nutrition congress. 4-7 September,Tehran, Iran,. 2016,

54.Amini M, Alavi-Naini A, Doustmohammadian Aa, Karajibani M, Khalilian A, Nouri-Saeedloo S, Salimi M,Shafaghi K. Childhood obesity and physical activity Patterns in an urban primary school in Thailand. Rawal Medical Journal, 2009. 34(2), 203-206

55.Worsley A. Nutrition knowledge and food consumption: can nutrition knowledge change food behaviour? Asia Pac J Clin Nutr, 2002. 11 Suppl 3, S57985.PMID: 12492651

56.Manios Y, Moschonis G, Grammatikaki E, Mavrogianni C, van den Heuvel EG, Bos R,Singh-Povel C. Food group and micronutrient intake adequacy among children, adults and elderly women in Greece. Nutrients, 2015. 7(3), 1841-58.PMCID: PMC4377885 doi:10.3390/nu7031841

57.Safavi S, Omidvar N, Djazayery A, Minaie M, Hooshiarrad A,Sheikoleslam R. Development of food-based dietary guidelines for Iran: A preliminary report. Annals of Nutrition and Metabolism, 2007. 51(Suppl. 2), 32-35

58.Ali HI, Ng SW, Zaghloul S, Harrison GG, Qazaq HS, El Sadig M,Yeatts K. High proportion of 6 to 18-year-old children and adolescents in the United Arab Emirates are not meeting dietary recommendations. Nutr Res, 2013. 33(6), 447-56.PMID: 23746560 doi:10.1016/j.nutres.2013.03.008

59.Dallongeville J, Marecaux N, Cottel D, Bingham A,Amouyel P. Association between nutrition knowledge and nutritional intake in middle-aged men from Northern France. Public Health Nutr, 2001. 4(1), 27-33.PMID: 11255493

\section{Tables}

Table 1: Recommended portions for 9 to 13-year-old children and portion sizes of food items within the five food groups based on the USDA My Plate [33]

\begin{tabular}{|c|c|c|}
\hline Food Group & Recommended Portions & Portion Size \\
\hline Grains & $\begin{array}{l}5 \text { portions (oz. equivalents) for } \\
\text { girls } \\
6 \text { portions (oz. equivalents) for } \\
\text { boys }\end{array}$ & 1 ounce equivalent of grains, such as a regular slice of bread, 0.5 cups cooked pasta or rice \\
\hline Dairy & 3 portions (cup equivalents) & $\begin{array}{l}1 \text { cup of milk, } 1 \square \text { ounces hard cheese (cheddar, mozzarella, Swiss, Parmesan), } 2 \text { cups cottage cheese and } 1 \text { cup } \\
\text { of yogurt }\end{array}$ \\
\hline $\begin{array}{l}\text { Protein } \\
\text { Foods }\end{array}$ & 5 portions (oz. equivalents) & 1 ounce of meat, poultry or seafood, 1 egg, 0.5 ounces of nuts or seeds, 0.25 cup of cooked legumes \\
\hline Fruits & 1.5 portions (cup equivalents) & 1 cup of fresh fruit, 0.5 cups of dried fruit, 1 cup of fresh fruit juice. \\
\hline Vegetables & $\begin{array}{l}2 \text { portions (cup equivalents) for } \\
\text { girls } \\
2.5 \text { portions (cup equivalents) for } \\
\text { boys }\end{array}$ & 1 cup of raw or cooked vegetables or vegetable juice, 2 cups of raw leafy greens \\
\hline
\end{tabular}

Table 2: Food and nutrition literacy status by sex in 10-12 years old students in Tehran ${ }^{\dagger}$ 


\begin{tabular}{|c|c|c|c|c|c|}
\hline \multicolumn{2}{|c|}{ Food and nutrition literacy and its subscales } & \multirow{2}{*}{$\begin{array}{c}\text { Total } \\
\mathrm{N}(\%)\end{array}$} & \multirow{2}{*}{$\begin{array}{c}\text { Boys } \\
\text { N (\%) }\end{array}$} & \multirow{2}{*}{$\begin{array}{c}\text { Girls } \\
\mathrm{N}(\%)\end{array}$} & \multirow[t]{2}{*}{ P value* } \\
\hline & & & & & \\
\hline FNLIT & Overall & 800 & 419 & 381 & \\
\hline \multirow[t]{4}{*}{ Total score } & Food and nutrition literacy (FNLIT) & & & & 0.39 \\
\hline & Low & 93(11.6) & $52(12.4)$ & $41(10.8)$ & \\
\hline & Moderate & $516(64.5)$ & $261(62.3)$ & $255(66.9)$ & \\
\hline & High & 191(23.9) & $106(25.3)$ & $85(22.3)$ & \\
\hline \multirow[t]{4}{*}{ cognitive domain } & FNLIT cognitive domain & & & & 0.06 \\
\hline & Low & $21(2.6)$ & $15(3.6)$ & $6(1.6)$ & \\
\hline & Moderate & $229(28.6)$ & $129(30.8)$ & $100(26.2)$ & \\
\hline & High & $550(68.8)$ & $275(65.6)$ & $275(72.2)$ & \\
\hline \multirow[t]{8}{*}{ cognitive domain subscales } & Understanding Food and nutrition info & & & & 0.19 \\
\hline & Low & $64(8)$ & $40(9.5)$ & $24(6.3)$ & \\
\hline & Moderate & $343(42.9)$ & $181(43.2)$ & $162(42.5)$ & \\
\hline & High & $393(49.1)$ & 198(47.3) & $195(51.2)$ & \\
\hline & Nutritional health knowledge & & & & 0.13 \\
\hline & Low & $30(3.8)$ & $21(5)$ & $9(2.4)$ & \\
\hline & Moderate & $77(9.6)$ & $41(9.8)$ & $36(9.4)$ & \\
\hline & High & $(86.6) 693$ & $357(85.2)$ & $336(88.2)$ & \\
\hline \multirow[t]{4}{*}{ skill domain } & FNLIT skill domain & & & & 0.96 \\
\hline & Low & $200(25)$ & $106(25.3)$ & $94(24.7)$ & \\
\hline & Moderate & $479(59.9)$ & $249(59.4)$ & $230(60.3)$ & \\
\hline & High & $121(15.1)$ & $64(15.3)$ & $57(15.0)$ & \\
\hline \multirow[t]{19}{*}{ skill domain subscales } & Functional food and nutrition literacy & & & & 0.24 \\
\hline & Low & $195(24.4)$ & $92(21.9)$ & $103(27.0)$ & \\
\hline & Moderate & $366(45.8)$ & $198(47.3)$ & $168(44.1)$ & \\
\hline & High & $239(29.9)$ & $129(30.8)$ & $110(28.9)$ & \\
\hline & Interactive food and nutrition literacy & & & & 0.69 \\
\hline & Low & $227(28.4)$ & $117(27.9)$ & $110(28.9)$ & \\
\hline & Moderate & $286(35.8)$ & $146(34.8)$ & $140(36.7)$ & \\
\hline & High & $287(35.9)$ & $156(37.2)$ & $131(34.4)$ & \\
\hline & Critical food and nutrition literacy & & & & $0.01^{*}$ \\
\hline & Low & $342(42.2)$ & $160(38.2)$ & $82(47.8)$ & \\
\hline & moderate & $298(37.3)$ & 163(38.9) & $135(35.4)$ & \\
\hline & high & $160(20)$ & $96(22.9)$ & $64(16.8)$ & \\
\hline & Food choice literacy & & & & $0.002^{*}$ \\
\hline & low & $62(7.8)$ & $46(11)$ & $16(4.2)$ & \\
\hline & moderate & $185(23.1)$ & $92(22)$ & $93(24.4)$ & \\
\hline & high & $553(69.1)$ & $281(67.1)$ & $272(71)$ & \\
\hline & Food label literacy & & & & 0.47 \\
\hline & low & $649(81.1)$ & $344(82.1)$ & $305(80.1)$ & \\
\hline & high & $151(18.9)$ & $75(17.9)$ & $76(19.9)$ & \\
\hline
\end{tabular}

${ }^{\dagger}$ FNLIT including cognitive and skill domains of food and nutrition literacy. FNLIT cognitive domain including understanding food information and nutritional health knowledge; FNLIT skill domain including functional, interactive, critical food and nutrition literacy, food choice and food label literacy.*Significant at $\mathrm{p}<0.05$ for independent-sample t-test

able 3: Mean \pm SD portions of food groups, DDS ${ }^{\dagger}$ and percentages with consumption below the recommended portions for each food group in 10-12 years old students in ehran

\begin{tabular}{|c|c|c|c|c|}
\hline & Total & $\begin{array}{c}\text { Boys } \\
\text { N (\%) }\end{array}$ & $\begin{array}{c}\text { Girls } \\
\text { N (\%) }\end{array}$ & P value* \\
\hline & 493 & $223(45.2)$ & $270(54.8)$ & \\
\hline \multirow[t]{3}{*}{ Food Groups } & Mean \pm SD & Mean \pm SD & Mean \pm SD & \\
\hline & Portions & Portions & Portions & \\
\hline & $\mathrm{N}(\%)<$ Recommended & $\mathrm{N}(\%)<$ Recommended & $\mathrm{N}(\%)<$ Recommended & \\
\hline \multirow[t]{2}{*}{ Grains } & $10.02 \pm 3.04$ & $10.53 \pm 3.30$ & $9.59 \pm 2.72$ & $0.001 *$ \\
\hline & $23(4.7)$ & $10(4.5)$ & $13(4.8)$ & 0.51 \\
\hline \multirow[t]{2}{*}{ Dairy } & $1.71 \pm 0.94$ & $1.72 \pm 1.00$ & $1.71 \pm 0.89$ & 0.94 \\
\hline & $452(91.7)$ & 204(91.5) & 248(91.9) & 0.50 \\
\hline \multirow[t]{2}{*}{ Protein Foods } & $3.64 \pm 1.85$ & $3.95 \pm 2.13$ & $3.38 \pm 1.54$ & $0.001 *$ \\
\hline & $403(81.7)$ & $171(76.7)$ & $232(85.9)$ & $0.01^{\S}$ \\
\hline \multirow[t]{2}{*}{ Fruits } & $2.27 \pm 1.75$ & $2.30 \pm 2.02$ & $2.24 \pm 1.49$ & 0.69 \\
\hline & 189(38.3) & $86(38.6)$ & $103(38.1)$ & 0.92 \\
\hline \multirow[t]{2}{*}{ Vegetables } & $3.91 \pm 2.21$ & $3.69 \pm 1.96$ & $4.09 \pm 2.39$ & $0.04^{*}$ \\
\hline & $107(21.7)$ & $58(26)$ & $49(18.1)$ & $0.03^{\S}$ \\
\hline DDS $($ Mean \pm SD) & $4.95 \pm 1.12$ & $4.95 \pm 1.13$ & $4.96 \pm 1.11$ & 0.93 \\
\hline
\end{tabular}

P-value $<0.05$ for the comparisons of mean values between boys and girls using independent sample t-test.

?-value $<0.05$ for the comparisons of percentages between boys and girls using the chi-square test.

$\S$ DDS, Diet Diversity Score 
Table 4: Adjusted ${ }^{\dagger}$ Odd Rasios (95\% CI) of food groups' intake ${ }^{\ddagger}$ for FNLIT scale and its subscales in 10-12 years students in Tehran ( $\mathrm{n}=493$ )

\begin{tabular}{|c|c|c|c|c|c|}
\hline \multirow[t]{2}{*}{ Food Groups } & Grains & Fruits & Vegetables & Dairy & Protein Foods \\
\hline & $<$ Recommended ${ }^{\pi}$ & $<$ Recommended & $<$ Recommended & $<$ Recommended & $<$ Recommended \\
\hline \multicolumn{6}{|c|}{ Low FNLIT ${ }^{\S}$} \\
\hline Yes & $1.43(0.16-12.23)$ & $0.74(0.39-1.39)$ & $0.69(0.25-1.85)$ & $1.08(0.21-5.59)$ & 3.49(0.99-12.34) \\
\hline No & 1 & 1 & 1 & 1 & 1 \\
\hline \multicolumn{6}{|l|}{ Low UFNI } \\
\hline Yes & $0.93(0.12-7.27)$ & $2.37(0.99-5.65)$ & $2.83(1.12-7.17)^{*}$ & $0.39(0.08-1.85)$ & $2.37(1.01-5.55)^{*}$ \\
\hline No & 1 & 1 & 1 & 1 & 1 \\
\hline \multicolumn{6}{|l|}{ Low NHK } \\
\hline Yes & $4.34(0.28-1.66)$ & $0.60(0.15-2.37)$ & $3.78(0.99-14.40)$ & $0.50(0.04-5.37)$ & $1.46(0.16-13.4)$ \\
\hline No & 1 & 1 & 1 & 1 & 1 \\
\hline \multicolumn{6}{|l|}{ Low FFNL } \\
\hline Yes & $0.62(0.14-2.69)$ & $2.42(1.38-4.25)^{*}$ & $1.16(0.60-2.22)$ & $3.22(1 / 00-10.39)$ & $1.21(0.52-1.92)$ \\
\hline No & 1 & 1 & 1 & 1 & 1 \\
\hline \multicolumn{6}{|l|}{ Low IFNL } \\
\hline Yes & $0.50(0.13-1.94)$ & $0.78(0.47-1.30)$ & $1.13(0.63-2.03)$ & $0.92(0.39-2.18)$ & $1.00(0.52-1.92)$ \\
\hline No & 1 & 1 & 1 & 1 & 1 \\
\hline \multicolumn{6}{|l|}{ Low FCL } \\
\hline Yes & $1.28(0.16-9.99)$ & $1 / 06(0.41-2.74)$ & $1.45(0.50-4 / 19)$ & $0.80(0.17-3.74)$ & $1.87(0.51-6.78)$ \\
\hline No & 1 & 1 & 1 & 1 & 1 \\
\hline \multicolumn{6}{|l|}{ Low CFNL } \\
\hline Yes & $1.15(0.41-3.21)$ & $0.78(3.50-1.21)$ & $1.14(0.67-1.91)$ & $0.51(0.24-1.04)$ & $0.82(0.47-1.44)$ \\
\hline No & 1 & 1 & 1 & 1 & 1 \\
\hline \multicolumn{6}{|l|}{ Low FLL } \\
\hline Yes & $0.91(0.25-3.27)$ & $1.06(0.62-1.81)$ & $1.07(0.57-2.01)$ & $0.54(0.20-1.47)$ & $0.72(0.36-1.44)$ \\
\hline No & 1 & 1 & 1 & 1 & 1 \\
\hline
\end{tabular}

${ }^{\dagger}$ Adjusted for sex, school status (governmental and nongovernmental), grade, birth rank, family size, ethnicity, parents' age, parents' education, father's job position, mother's employment, Other income source of family members, house ownership status, financial support source, physical activity, household food security, weight status and calorie intake.

‡ Binary logistic regression comparing food group category to $\geq$ Recommended

$\S$ FNLIT, Food and Nutrition Literacy; Cognitive subscales including: UFNI, Understanding Food and Nutrition Literacy; NHK, Nutritional Health Knowledge; Skill subscales including; FFNL, Functional Food and Nutrition Literacy IFNL, Interactive Food and Nutrition Literacy; FCL, Food Choice Literacy; CFNL, Critical Food and Nutrition Literacy; FLL, Food Label Literacy. ${ }^{\top}$ Recommended daily consumption: (i) dairy, three portions (cup equivalents);(ii) protein foods, five portions (oz. equivalents); (iii) fruits, 1.5 portions (cup equivalents); (iv) vegetables, two portions (cup equivalents) for girls and 2.5 portions (cup equivalents) for boys; (v) grains, five portions (oz. equivalents) for girls and six portions (oz. equivalents) for boys [33].

*Significant at $\mathrm{p}<0.05$

Table 5: Adjusted ${ }^{\ddagger}$ Odd Ratios (95\% CI) of nutrient adequacy ratio [2] of certain nutrients for FNLIT scale and its subscales in 10-12 years students in Tehran ( $=493$ ) $§$ 


\begin{tabular}{|c|c|c|c|c|c|c|c|c|c|c|c|c|}
\hline \multirow[t]{2}{*}{ NAR } & \multicolumn{2}{|c|}{ MAR } & \multicolumn{2}{|c|}{ NAR pro } & \multicolumn{2}{|c|}{$\mathrm{NAR}_{\mathrm{B}_{9}}$} & \multicolumn{2}{|c|}{ NAR $B_{6}$} & \multicolumn{2}{|c|}{ NAR $B_{3}$} & \multicolumn{2}{|c|}{ NAR calcium } \\
\hline & $\mathrm{T} 1$ & $\mathrm{~T} 2$ & $\mathrm{~T} 1$ & $\mathrm{~T} 2$ & T1 & $\mathrm{T} 2$ & $\mathrm{~T} 1$ & $\mathrm{~T} 2$ & $\mathrm{~T} 1$ & $\mathrm{~T} 2$ & $\mathrm{~T} 1$ & $\mathrm{~T} 2$ \\
\hline \multicolumn{13}{|l|}{ Low } \\
\hline \multicolumn{13}{|l|}{$\begin{array}{l}\text { FNLIT } \\
\text { a }\end{array}$} \\
\hline \multirow[t]{2}{*}{ Yes } & 1.33 & 0.80 & 2.47 & 2.02 & 0.85 & 0.88 & 1.49 & 1.37 & 0.79 & 0.48 & 1.24 & 0.81 \\
\hline & $(0.38,4.54)$ & $(0.29,2.15)$ & $(0.61,10.02)$ & $(1.02,8.95)$ & $(0.31,2.35)$ & $(0.33,2.32)$ & $(0.50,4.44)$ & $(0.52,3.58)$ & $(0.23,2.66)$ & $(0.17,1.37)$ & $(0.43,3.60)$ & $(0.26,2.39)$ \\
\hline No & 1 & 1 & 1 & 1 & 1 & 1 & 1 & 1 & 1 & 1 & 1 & 1 \\
\hline \multicolumn{13}{|l|}{ Low } \\
\hline \multicolumn{13}{|l|}{ UFNI } \\
\hline \multirow[t]{2}{*}{ Yes } & 2.94 & 2.91 & 0.32 & 0.38 & 2.98 & 1.44 & 0.84 & 1.03 & 1.26 & 0.91 & 0.34 & 0.45 \\
\hline & $(0.82,10.44)$ & $(1.03,8.23)$ & $(0.08,1.29)$ & $(0.14,1.06)$ & $(1.04,8.51)$ & $(0.52,3.99)$ & $(0.28,2.54)$ & $(0.39,2.69)$ & $(0.40,3.93)$ & $(0.32,2.57)$ & $(0.12,1.01)$ & $(0.17,1.20)$ \\
\hline No & 1 & 1 & 1 & 1 & 1 & 1 & 1 & 1 & 1 & 1 & 1 & 1 \\
\hline \multicolumn{13}{|l|}{ Low } \\
\hline \multicolumn{13}{|l|}{ FFNL } \\
\hline \multirow[t]{2}{*}{ Yes } & 3.12 & 1.72 & 2.33 & 1.67 & 1.75 & 1.03 & 2.30 & 1.32 & 0.61 & 0.78 & 2.98 & 2.34 \\
\hline & $(1.38,7.05)$ & $(0.91,3.24)$ & $(0.98,5.52)$ & $(0.84,3.30)$ & $(0.89,3.42)$ & $(0.58,2.03)$ & $(1.10,4.83)$ & $(0.70,2.47)$ & $(0.27,1.36)$ & $(0.39,1.57)$ & $(1.46,6.11)$ & $(1.16,4.76)$ \\
\hline No & 1 & 1 & 1 & 1 & 1 & 1 & 1 & 1 & 1 & 1 & 1 & 1 \\
\hline \multicolumn{13}{|l|}{ Low } \\
\hline \multicolumn{13}{|l|}{ FCL } \\
\hline \multirow[t]{2}{*}{ Yes } & 0.83 & 0.75 & 0.84 & 1.13 & 0.81 & 1.16 & 2.10 & 0.97 & 3.65 & 2.35 & 0.73 & 0.89 \\
\hline & $(0.23,2.96)$ & $(0.27,2.09)$ & $(0.18,3.83)$ & $(0.37,3.41)$ & $(0.26,2.47)$ & $(0.43,3.08)$ & $(0.67,6.54)$ & $(0.35,2.69)$ & $(1.05,12.69)$ & $(0.78,7.08)$ & $(0.43,1.25)$ & $(0.53,1.49)$ \\
\hline No & 1 & 1 & 1 & 1 & 1 & 1 & 1 & 1 & 1 & 1 & 1 & 1 \\
\hline \multicolumn{13}{|l|}{ Low } \\
\hline \multicolumn{13}{|l|}{ FLL } \\
\hline Yes & 0.83 & 0.98 & 0.94 & 1.15 & 0.92 & 0.84 & 1.31 & 1.41 & 0.59 & 0.89 & 1.11 & 2.28 \\
\hline & $(0.37,4.38)$ & $(0.54,1.77)$ & $(0.41,2.16)$ & $(0.61,2.19)$ & $(0.47,1.82)$ & $(0.47,1.50)$ & $(0.63,2.71)$ & $(0.77,2.57)$ & $(0.28,1.27)$ & $(0.44,1.79)$ & $(0.58,2.11)$ & $(1.16,4.49)$ \\
\hline No & 1 & 1 & 1 & 1 & 1 & 1 & 1 & 1 & 1 & 1 & 1 & 1 \\
\hline
\end{tabular}

† FNLIT, Food and Nutrition Literacy; Cognitive subscales including: UFNI, Understanding Food and Nutrition Literacy; NHK, Nutritional Health Knowledge; Skill subscales including; FFNL, Functional Food and Nutrition Literacy IFNL, Interactive Food and Nutrition Literacy; FCL, Food Choice Literacy; CFNL, Critical Food and Nutrition Literacy; FLL, Food Label Literacy. ${ }^{\ddagger}$ Multinomial logistic regression, adjusted for sex, school status (governmental and nongovernmental), grade, birth rank, family size, ethnicity, parents' age, parents' education, father's job position, mother's employment, Other income source of family members, house ownership status, financial support source, physical activity, household food security, weight status and calorie intake

§Only those variables that were significantly associated with FNLIT and its subscales were reported.

*Significant at $\mathrm{p}<0.05$

Table 6: Adjusted ${ }^{\ddagger}$ Odd Ratios (95\% CI) of Dietary Diversity Score (DDS) for FNLIT scale and its subscales in 10-12 years students in Tehran (n=493) ${ }^{\S}$

\begin{tabular}{|c|c|c|c|c|c|c|c|c|}
\hline \multirow[t]{2}{*}{ Groups } & \multicolumn{2}{|c|}{ DDS } & \multicolumn{2}{|c|}{ Fruits } & \multicolumn{2}{|c|}{ Dairies } & \multicolumn{2}{|c|}{ Protein Foods } \\
\hline & T1 & $\mathrm{T} 2$ & T1 & $\mathrm{T} 2$ & T1 & $\mathrm{T} 2$ & T1 & $\mathrm{T} 2$ \\
\hline \multicolumn{9}{|c|}{ Low NHK } \\
\hline Yes & $\begin{array}{c}2.72 \\
(044.1663)\end{array}$ & $\begin{array}{c}3.40 \\
(0.56 .20 .51)\end{array}$ & $\begin{array}{c}1.11 \\
(0.58211)\end{array}$ & $\begin{array}{l}3.82 * \\
(14.42)\end{array}$ & $\begin{array}{c}0.41 \\
(0.03488)\end{array}$ & $\begin{array}{c}0.89 \\
(0.071027)\end{array}$ & $\begin{array}{c}2.33 \\
(0.192789)\end{array}$ & $\begin{array}{c}4.77 \\
(0.5144\end{array}$ \\
\hline No & $\begin{array}{c}(0.44,16.63) \\
1\end{array}$ & $\begin{array}{c}(0.56,20.51) \\
1\end{array}$ & $\begin{array}{c}(0.58,2.11) \\
1\end{array}$ & $\begin{array}{c}(1.01,14.42) \\
1\end{array}$ & $\begin{array}{c}(0.03,4.88) \\
1\end{array}$ & $\begin{array}{c}(0.07,10.27) \\
1\end{array}$ & $\begin{array}{c}(0.19,27.89) \\
1\end{array}$ & $\begin{array}{c}(0.51,44.17) \\
1\end{array}$ \\
\hline \multicolumn{9}{|c|}{ Low FFNL } \\
\hline Yes & $\begin{array}{c}2.72^{*} \\
(1.38,5.34)\end{array}$ & $\begin{array}{c}0.99 \\
(0.49,1.99)\end{array}$ & $\begin{array}{c}4.87 * \\
(2.13,11.08)\end{array}$ & $\begin{array}{c}1.67 \\
(0.92,3.01)\end{array}$ & $\begin{array}{c}19.5^{*} \\
(2.09,182.38)\end{array}$ & $\begin{array}{c}11.49 * \\
(1.21,108.60)\end{array}$ & $\begin{array}{c}1.03 \\
(0.49,2.18)\end{array}$ & $\begin{array}{c}0.78 \\
(0.40,1.49)\end{array}$ \\
\hline No & 1 & 1 & 1 & 1 & 1 & 1 & 1 & 1 \\
\hline \multicolumn{9}{|c|}{ Low IFNL } \\
\hline Yes & $\begin{array}{c}1.18 \\
(0.65,2.14)\end{array}$ & $\begin{array}{c}0.91 \\
(0.51,1.64)\end{array}$ & $\begin{array}{c}0.87 \\
(0.40,1.89)\end{array}$ & $\begin{array}{c}0.91 \\
(0.54,1.52)\end{array}$ & $\begin{array}{c}0.92 \\
(0.35,2.36)\end{array}$ & $\begin{array}{c}0.90 \\
(0.34,2.39)\end{array}$ & $\begin{array}{c}1.11 \\
(0.54,2.30)\end{array}$ & $\begin{array}{c}2.48^{*} \\
(1.34,4.57)\end{array}$ \\
\hline No & 1 & 1 & 1 & 1 & 1 & 1 & 1 & 1 \\
\hline \multicolumn{9}{|c|}{ Low FLL } \\
\hline Yes & $\begin{array}{c}1.92 \\
(1.00,3.71)\end{array}$ & $\begin{array}{c}1.08 \\
(0.38,3.02)\end{array}$ & $\begin{array}{c}1.26 \\
(0.53,2.96)\end{array}$ & $\begin{array}{c}1.35 \\
(0.77,2.37)\end{array}$ & $\begin{array}{c}1.98 \\
(0.81,4.86)\end{array}$ & $\begin{array}{c}2.68 \\
(1.05,6.89)\end{array}$ & $\begin{array}{c}1.96 \\
(0.97,3.96)\end{array}$ & $\begin{array}{c}2.40^{*} \\
(1.31,4.40)\end{array}$ \\
\hline No & 1 & 1 & 1 & 1 & 1 & 1 & 1 & 1 \\
\hline
\end{tabular}

${ }^{\dagger}$ FNLIT, Food and Nutrition Literacy; Cognitive subscales including: UFNI, Understanding Food and Nutrition Literacy; NHK, Nutritional Health Knowledge; Skill subscales including; FFNL, Functional Food and Nutrition Literacy IFNL, Interactive Food and Nutrition Literacy; FCL, Food Choice Literacy; CFNL, Critical Food and Nutrition Literacy; FLL, Food Label Literacy. ${ }^{\ddagger}$ Multinomial logistic regression, adjusted for sex, school status (governmental and nongovernmental), grade, birth rank, family size, ethnicity, parents' age, parents' education, father's job position, mother's employment, Other income source of family members, house ownership status, financial support source, physical activity, household food security, weight status and calorie intake

${ }^{\S}$ Only those variables that were significantly associated with FNLIT and its subscales were reported.

*Significant at $\mathrm{p}<0.05$

\section{Figures}




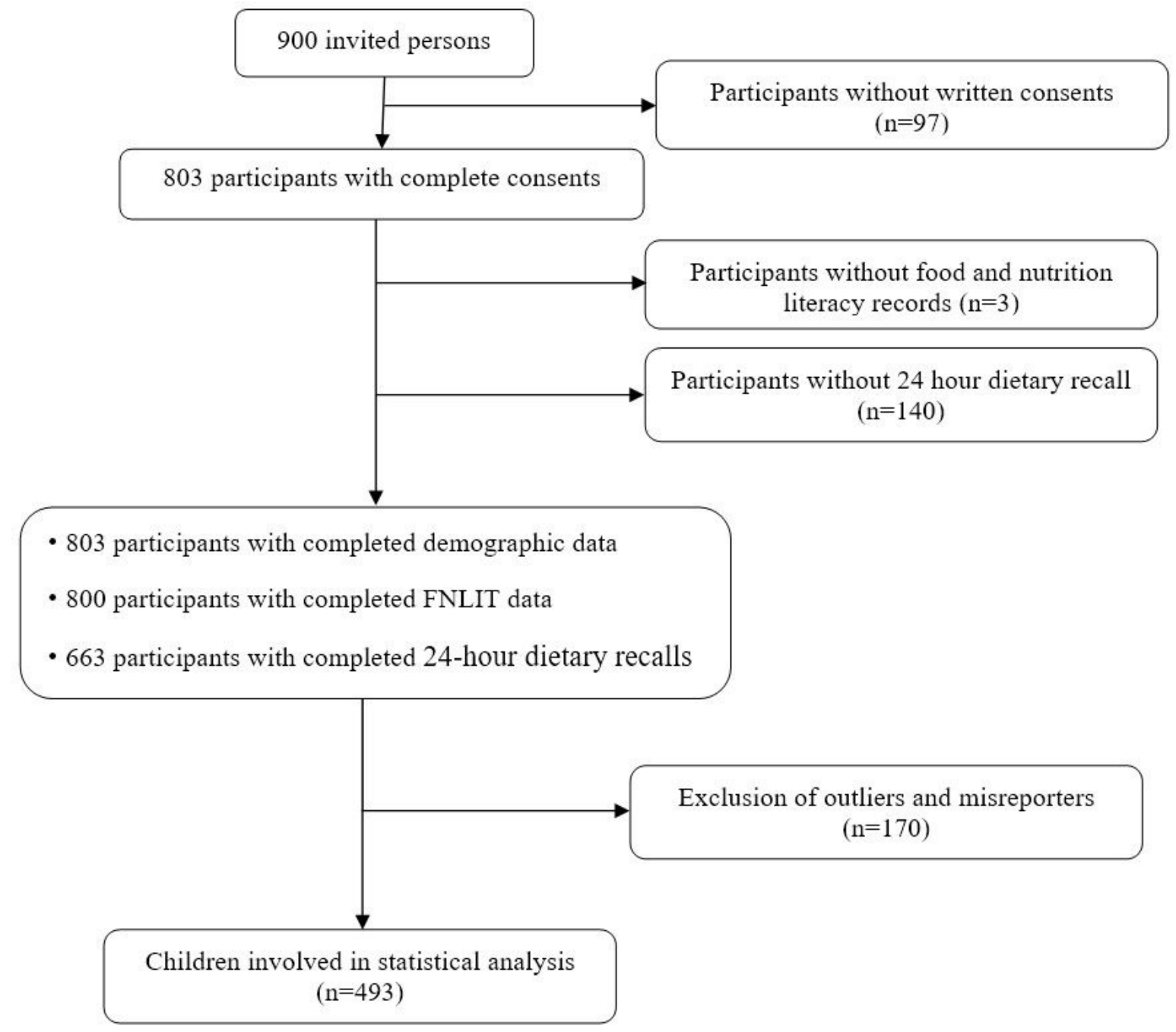

Figure 1

STROBE study conduct and participant flow of the study 


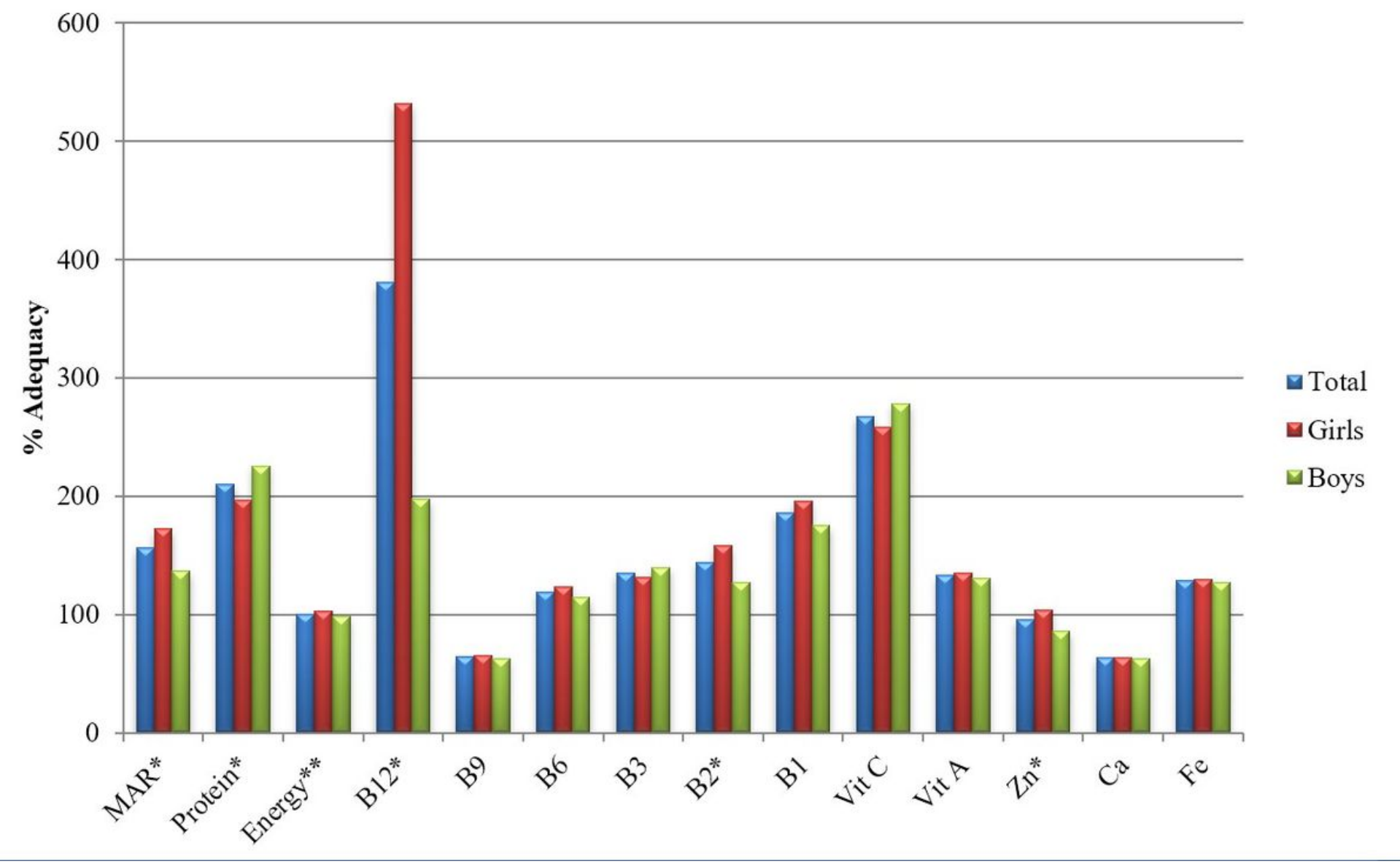

Figure 2

The nutrient adequacy ratio percent of certain nutrients by sex in 10-12 years students in Tehran $(n=493) *$ Significant at $p<0.001$ for $t$-test $* \star$ Significant at $p<0.05$ for t-test

\section{Supplementary Files}

This is a list of supplementary files associated with this preprint. Click to download.

- SupplementaryMaterials.docx 